\title{
An Unusual Case of Thyroglossal Duct Cyst Mimicking Laryngopyocele in an Elderly Patient
}

The Editor,

Sir,

Thyroglossal duct cyst (TGDC) is the most common developmental abnormality of the thyroid gland that arises from a tubal remnant of thyroid descent during migration (1). It accounts for $70 \%$ of congenital neck masses. In $76 \%$ of cases, the cyst occurs before age six year (2). While it is the most common congenital neck mass in children, occurrence of the disease in elderly patients is rare (3). In this paper, we reported an elderly patient with TGDC presenting as a lateral neck mass with intralaryngeal extension. Apart from his age, localization and presentation of the cyst, our case was different from other common cases.

A 60-year old man presented with a swelling which had been growing for three years at the left-neck region. Physical examination revealed a soft, painless mass at the anterior border of the left sternocleidomastoid muscle. At endoscopic laryngeal examination, swelling at the anterior commissure, which causes minimal obstruction in airway, was observed. A computerized tomography $(\mathrm{CT})$ was performed which revealed a regular boarded cystic mass located inferior to the hyoid bone and extending towards the left-side of the neck, $3 \times 5.5 \mathrm{~cm}$ in diameter. (Fig. 1) At the axial plane intralaryngeal extension of the cyst was observed.

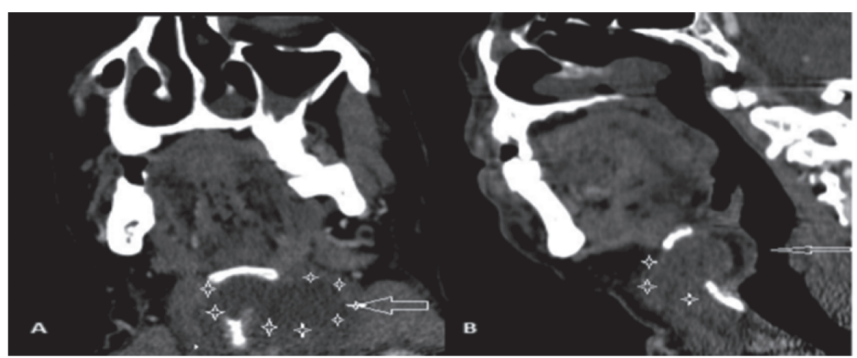

Fig. 1: Computerize tomography showed a regular boarded cystic mass A-Sagittal plane showed the mass located between hyoid bone and thyroid cartilage. B- Coronal plane showed the mass extending towards the left-side of the neck.

These CT raised the diagnosis of a laryngopyocele. Under general anaesthesia, excision of the mass was performed. During the operation, it was observed that the mass has a duct extending upwards through the hyoid bone. The patient was diagnosed as TGDC and a sistrunk procedure was performed. The histopathological result was TGDC. The patient had no complaints during the follow-up period.

Thyroglossal duct cyst occurs according to failure to involute and atrophy of TGD in the embryological period (3). It

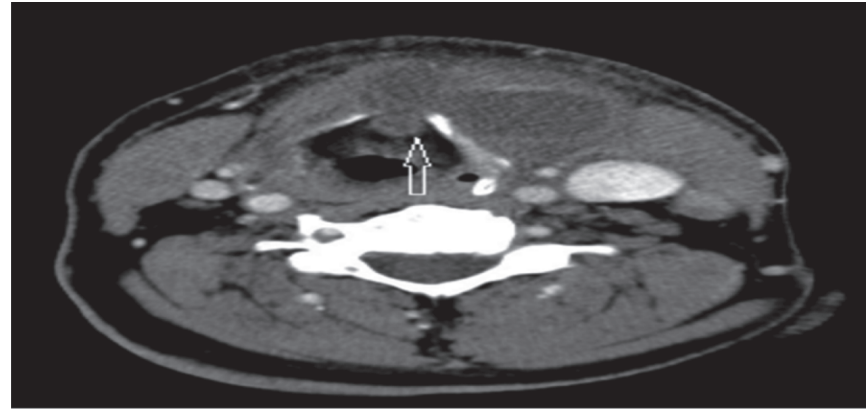

Fig. 2: Axial computerized tomography showed intralaryngeal extension of the cyst (arrow).

can be located anywhere along the path of TGD, between the foramen caecum and the suprasternal notch and generally presents as a slow growing, painless swelling at the midline of the neck which pathognomically moves with tongue protrusion or swallowing $(2,4,5)$. Intralaryngeal extension of TGDC is extremely rare (6), but when it occurs, the appearance is similar to a laryngopyocele. Dermoid or epidermoid cysts, branchial cleft cyst, lymph nodes, thyroid pathologies must also be thought of in the differential diagnosis of TGDC (5).

The treatment of TGDC is surgery. The surgical procedure was described by Sistrunk in 1920 (7). The sistrunk procedure includes removal of the cyst with its tract, the body of hyoid bone and the tissue from the tract to the foremen caecum. It was reported that if the hyoid bone is not removed the recurrence rate is $85 \%$ while the recurrence rate decreases to the $2 \%$ with removal of the hyoid bone (3).

Besides TGDC generally occurs as a midline neck mas, it must be kept in mind that it may have unexpected presentations such as lateral neck masses and intralaryngeal extension even in elderly patients.

Keywords: Intralaryngeal extension, laryngopyocele, sistrunk procedure, thyroglossal duct cyst

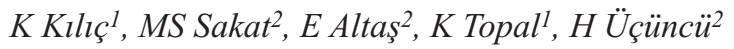

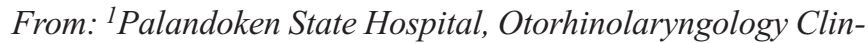
ics, Erzurum, Turkey and ${ }^{2}$ Ataturk University, Faculty of Medicine, Department of Otorhinolaryngology, Erzurum, Turkey

Correspondence: Dr H Ucuncu, Department of Otorhinolaryngology, Faculty of Medicine, Ataturk University, Erzurum 25240, Turkey. Fax: +90-442-236 1301, e-mail: hucuncu61@gmail.com 


\section{REFERENCES}

1. Pietruszewska W, Wągrowska-Danilewicz M, Jozefowicz-Korczynska. Papillary carcinoma in thyroglossal duct cyst with uninvolved thyroid; Case report and review of the literature. Arch Med Sci 2014; 10: 10615.

2. Karmakar S, Saha AM, Mukherjee D. Thyroglossal cyst: an unusual presentation. Indian J Otolaryngol Head Neck Surg 2013; 65: 185-7.

3. Baisakhiya N. Giant thyroglossal cyst in an elderly patient. Indian $J$ Otolaryngol Head Neck Surg 2011; 63: 27-8.
4. Naghavi SE, Jalali MM. Papillary carcinoma of thyroglossal duct cyst. Med Sci Monit 2003; 9: 67-70.

5. Tarcoveanu E, Niculescu D, Vasilescu A, Ferariu D. Thyroglossal duct cyst. Jurnalul de Chirurgie 2009; 5: 45-51.

6. Kurien R, Michael R. Subglottic thyroglossal duct cyst: A rare intralaryngeal presentation.Ear Nose Throat J 2012; 91: 15-9.

7. Sistrunk We. The surgical treatment of cysts of the thyroglossal tract. Ann Surg 1920; 71: 121-2. 